\section{O modelo biomédico e a reformulação do currículo médico da Universidade Federal Fluminense}

The biomedical model and the reformulation of the medical curriculum of Universidade Federal Fluminense

\section{Lilian Koifman}

Doutoranda em saúde pública na Escola Nacional de Saúde Pública da Fundação Oswaldo Cruz (ENSP/Fiocruz) Rua General Glicério, 445/601 22245-120 Rio de Janeiro - RJ Brasil liliankoifman@hotmail.com
KOIFMAN, L.: 'O modelo biomédico e a reformulação do currículo médico da Universidade Federal Fluminense'. História, Ciências, Saúde - Manguinhos, vol. VIII (1): 48-70, mar.-jun. 2001.

Este artigo analisa a construção do modelo a partir do qual vem se baseando o currículo das faculdades de medicina nas Américas e na maioria dos países europeus. Críticas que vêm sendo feitas a esse modelo são identificadas na reformulação curricular do curso de medicina da Universidade Federal Fluminense (UFF).

A análise do documento de reformulação curricular da UFF, de 1992, bem como sua comparação com o currículo anterior, à luz da história do modelo biomédico, da teoria curricular e da epistemologia de Ludwik Fleck, aponta em que medida essa reformulação significa uma alternativa ao modelo biomédico de formação dos médicos, ao reducionismo do ser humano ao seu organismo biológico.

O novo currículo - com um aumento de $25 \%$ da carga horária e a introdução de grande número de aulas práticas, desde o início do curso apesar de ainda estar centrado nos aspectos biológicos, já se volta para uma formação mais humanista e se propõe a questionar as "verdades científicas".

PALAVRAS-CHAVE: modelo biomédico, educação médica, currículo médico, reformulação do currículo médico.

KOIFMAN, L.: 'The biomedical model and the reformulation of the medical curriculum of Universidade Federal Fluminense'.

História, Ciências, Saude - Manguinhos, vol. VIII(1): 48-70, Mar.-June 2001.

This work reviews the model used as basis for the curricula of medical universities in North and South America as well as in most European countries. Some criticism about this model is identified on the curricular reformulation of the medicine course of Universidade Federal Fluminense (UFF).

The review of the document about curricular reformulation of UFF, from 1992, as well as how it compares to its previous curriculum regarding the history of the biomedical model, the curricular theory, and Ludwik Fleck's epistemology, measures the relevance of this reformulation as an alternative to the biomedical model of forming doctors and to the reductionism of the human being to its biological organism.

The new curriculum - with a $25 \%$ raise in credit hours and the inclusion of many new practical classes since the beginning of the course - although still focusing the biological aspects, already shows a more humanist formation and intends to question the "scientifical truths".

KEYWORDS: biomedical model, medical education, medical curriculum, reformulation of the medical curriculum. 


\section{Introdução}

T a primeira parte deste artigo, procuramos traçar a construção do 1 modelo biomédico através da trajetória de construção da racionalidade médica, em que os conceitos do normal e do patológico se estabeleceram. Abordamos, ainda, as raízes históricas da medicina social - para demonstrar que o movimento contemporâneo tem suas raízes no século passado - e chegamos ao Relatório Flexner, com suas conseqüências para a formação médica.

$\mathrm{Na}$ segunda parte, pretendemos discutir em que sentido a proposta de reformulação curricular da UFF, elaborada em 1992 e implantada em 1994, estabelece novas possibilidades de articulação entre o biológico e o social no estudo do processo saúde-doença, bem como os reflexos dessa articulação sobre o processo de formação de novos médicos. Desejamos indicar até que ponto essa proposta poderá refletir as críticas ao modelo biomédico, que vem sendo utilizado para a construção dos currículos de medicina.

A publicação do presente artigo, passados sete anos do início da implantação da nova proposta, coincide com o ano de formatura da segunda turma no novo currículo. Como o processo de implantação ainda é considerado um processo em andamento, sua análise continua válida. Esperamos que, a partir da experiência estudada, outros processos de reformulação curricular a serem realizados ou já em andamento possam se beneficiar e aproveitar a experiência vivida na Faculdade de Medicina da UFF.

O ensino médico no Brasil e no mundo vem sendo analisado e debatido pelos profissionais da área médica e pelos meios de comunicação, pela sociedade em geral. Há, de certa forma, um consenso quanto à insatisfação no atendimento da população e quanto à necessidade de reformulação de determinados aspectos da formação médica.

As propostas de mudanças no sistema de saúde, em especial no que concerne aos cuidados básicos com a saúde, não vêm sendo acompanhadas pelos currículos dos cursos de medicina. A educação médica no Brasil parece não valorizar o alcance de objetivos coerentes com a realidade social, nem elaborar planejamentos eficazes nesse sentido.

As análises históricas e sociológicas do desenvolvimento da medicina moderna e da formação do médico como categoria profissional têm sido influenciadas por visões que tendem a ressaltar ora o caráter autônomo do processo de trabalho profissional diante da sociedade, ora seu caráter subordinado às demandas objetivas de grupos sociais (Coe, 1984).

No que concerne à formação médica, é possível identificar dois processos quase independentes: uma extensa formação clínica, centrada nas ciências biomédicas - que reforça a prática individualista da medi- 
cina - e uma abordagem social, incapaz de redefinir criticamente essa formação e seus diferentes tipos de prática.

Este artigo pretende discutir em que sentido a proposta de reformulação curricular da UFF estabelece novas possibilidades de articulação entre o biológico e o social no estudo do processo saúdedoença, bem como os reflexos dessa articulação sobre o processo de formação de novos médicos.

A partir da análise do documento de reformulação do currículo de medicina da UFF, à luz da história do modelo biomédico e da epistemologia de Ludwik Fleck, objetivamos apontar em que medida tal reformulação significa uma alternativa ao modelo de formação dos médicos, no que diz respeito ao reducionismo do ser humano ao seu organismo biológico.

\section{A construção do modelo biomédico}

O deslocamento epistemológico - e clínico - da medicina moderna de arte de curar indivíduos doentes para disciplina das doenças supôs uma passagem histórica que se iniciou no Renascimento, final do século XV, e foi até o início do século XVI (Luz, 1988).

O movimento de ruptura das antigas maneiras de conceber o organismo humano se deu com a anatomia e instaurou uma nova racionalidade médica, moderna, que tinha como traço fundamental o mecanismo fisiologista do período clássico. Nessa concepção, a vida deixou de ser objeto central da prática médica (clínica), e a forma humana passou a ser vista como máquina. Ocorreu, então, segundo Luz (1988), a transformação da prática clínica. Os hospitais passaram a ser organizados como espaço clínico de uma ciência das entidades patológicas. O corpo humano tornou-se, então, a sede das doenças; e as doenças, entidades patológicas.

$\mathrm{Na}$ anatomia clínica do século XIX, o aprendizado das doenças se fez não pela observação da vida, mesmo que em corpos doentes, mas em corpos mortos, "traçando-se, a partir da visão da morte, os limites do trajeto da vida" (Luz, 1988, p. 89). Assim, a saúde passou a ser vista como ausência de doença e a cura passou a significar a eliminação dos sintomas.

Essa visão de doença é herança de uma história de cerca de três séculos: "Desde então, o método cartesiano tornou-se o paradigma dominante da ciência e o universo passou a ser concebido como um sistema mecânico, consistindo em objetos separados que, por sua vez, foram reduzidos a seus menores elementos materiais" (Vaitsman, 1992). A história da formação desse paradigma pode explicar os motivos de transformação, no século XIX, da disciplina das doenças em ciência do normal e do patológico.

Ao longo do tempo, os modos de expressão do adoecer e da doença foram se modificando. As formas de produção dos conhecimentos 
médicos influenciaram a relação da prática médica com o doente e a doença. Ocorreu um afastamento do médico em relação ao doente, e maior teorização dos discursos médicos.

A visão do doente pela instituição hospitalar, praticada pela medicina de beira-de-leito predominantemente no século XVIII, transcendeu as distinções entre mente e corpo encontradas na medicina moderna. Tratava-se de enfrentar a doença como manifestação de causas, subjetivas e externas, e se procurava alcançar uma causa universal da doença. Essa medicina baseava-se em uma patologia especulativa e em nosologias fenomenológicas (Luz, 1988).

Segundo Foucault (1980), desde o Renascimento, o ensino de clínica se organizava a partir da transmissão de um professor (tutor) diretamente para os alunos, em hospitais. Os casos deviam ser reunidos num "corpo da nosologia”, e a clínica se fechava sobre a totalidade didática de uma experiência ideal. Mais importante do que o encontro entre o doente e o médico era o de uma verdade a decifrar uma ignorância: o papel do médico de hospital era descobrir a doença. $\mathrm{O}$ paciente era visto apenas como o portador de uma doença.

Por outro lado, na clínica, se encontram doenças que o portador desconhece. Ainda segundo Foucault (1980), o que está presente é a doença no corpo que lhe é próprio, e este não é o do doente, mas o de sua verdade. A clínica constitui a expropriação da doença, e o indivíduo serve para sua enumeração, seu exemplo. A clínica tem a sua própria verdade sobre as doenças.

Para Foucault (op. cit., p. 67), o diagnóstico da doença "recolhe uma dupla verdade: uma, oculta, mas já presente, da doença; outra, claramente dedutivel, do fim e dos meios". Interpôs-se um véu entre o olhar do médico e o paciente: "Não é portanto o próprio olhar que tem poder de análise e síntese; mas a verdade de um saber discursivo que vem se acrescentar de fora."

A institucionalização da doença pelo médico provocou uma desconfiança do sofrimento do paciente, pois este não é, nessa maneira de ver, a expressão de uma doença dos órgãos. Essa abstração da doença - do doente - levou ao questionamento de Canguilhem: "O que é um sintoma sem contexto ou pano de fundo?"

Para Canguilhem (1990, pp. 66, 65), a clínica é um instrumento da prática médica, e o médico pode, junto ao paciente, diagnosticar as doenças para melhor lidar com a patologia. $\mathrm{O}$ autor defende a clínica, argumentando que a "doença do médico" só poderia ser compreendida "na experiência que os homens têm de suas relações de conjunto com o meio". O comportamento do clínico, muito mais fisiologista do que médico, capaz de entender a doença como "uma forma diferente de vida" do paciente, se deve a um falseamento do fato patológico objetivo, que ocorre porque "os sintomas subjetivos e os sintomas objetivos raramente coincidem um com o outro". Além disso, o fato de determinadas doenças possuírem períodos de latência variáveis e estágios 
subclínicos contribui para o médico "desconfiar" dos sintomas do paciente. Impõe-se uma noção: a doença do doente não é a mesma que a doença, anatômica, do médico.

A definição de doença válida do ponto de vista da ciência é a do médico, e não a do doente. "Leriche demonstra que o silêncio dos órgãos não equivale necessariamente à ausência de doença” (Canguilhem, op. cit., p. 68). Muitas vezes os órgãos estão doentes sem que apareçam sintomas.

Médicos e cirurgiões dispõem de informações clínicas e, às vezes, utilizam também técnicas de laboratório que lhes permitem saber que estão doentes pessoas que não se sentem doentes. Mas a medicina existe porque as pessoas se sentem doentes, e não porque existem médicos que as informam sobre suas doenças. A doença do doente não é a mesma do médico.

A medicina atual é oscilante quanto à questão da doença e do sofrimento. $\mathrm{O}$ médico preocupa-se com o seu desempenho técnico e, em sua formação, recebe informações ambíguas sobre o que valorizar nas queixas dos pacientes. Segundo Vieira (1991), os livros acadêmicos recomendam ao profissional que deixe os pacientes expressarem livremente suas moléstias, pois aí se fundamentaria o estabelecimento de uma relação médico-paciente em "clima de simpatia e confiança" (Surós apud Vieira, 1991). Mas, logo a seguir, esse autor salienta: "Sempre que possível, a anamnese deve vir animada de uma orientação ou intenção diagnóstica, omitindo detalhes sem interesse", para que não se torne "um trabalho dispersivo de diagnóstico". Vieira questiona: "Como pode estabelecer-se uma relação médico-paciente se o paciente só pode falar com limites?" Na verdade, terá o médico o direito de determinar o melhor para o paciente? Por vezes, o procedimento cientificamente mais indicado não garante mais anos de vida ao paciente, ou, ainda, anos de vida mais felizes.

Portanto, a formação médica - que torna o profissional cada vez mais distante do respeito ao desejo do paciente, o dono do "corpo que está sendo tratado" -, muitas vezes o leva a cometer erros por se considerar "dono do saber" e não escutar a opinião do "dono do corpo".

Em determinadas situações, a demanda do paciente se faz exclusivamente pelos exames complementares, o que o médico muitas vezes considera uma intromissão em sua área, em seu poder, criandose um confronto na consulta. O médico, por seu lado, sente-se cada vez menos confiante em seu "olho clínico" e, para atender seja à ansiedade do paciente, seja à sua própria, solicita exames.

A influência da tecnologia, exercida sobre o exame físico, repercute na relação médico-paciente. $O$ paciente se afasta, é afastado. A solicitação de um exame deveria ter como pressuposto básico o raciocínio clínico: no uso de um exame complementar estaria a necessidade de excluir ou confirmar um diagnóstico. $\mathrm{O}$ ato médico vem perdendo suas antigas 
características: a anamnese, uma vez que o médico não escuta o paciente; o exame físico, pois o médico não o examina. Sua substituição pelos exames complementares é preocupante, também, pelo fato de os médicos terem dificuldade de interpretar esses exames. A tecnologia interfere na terapêutica e na alta dos pacientes.

$\mathrm{Na}$ realidade, a introdução da tecnologia na medicina se insere em um processo mais amplo. No campo do saber médico, a influência do paradigma cartesiano sobre o pensamento médico resultou no chamado modelo biomédico, alicerce consensual da moderna medicina científica.

O modelo biomédico vê o corpo humano como uma máquina muito complexa, com partes que se inter-relacionam, obedecendo a leis natural e psicologicamente perfeitas. $O$ modelo biomédico pressupõe que a máquina complexa (o corpo) precise constantemente de inspeção por parte de um especialista. Assume-se, assim, de modo implícito, que alguma coisa, inevitavelmente, não estará bem dentro dessa complexa máquina. Não fosse por isto, por que as inspeções constantes? O modelo biomédico não vê o corpo como uma máquina perfeita, mas como uma máquina que tem, ou terá, problemas, que só especialistas podem constatar.

O fenômeno biológico é explicado pela química e pela física. Não parece haver espaço, portanto, dentro dessa estrutura, para as questões sociais, psicológicas e para as dimensões comportamentais das doenças. Acredita-se serem as doenças resultado ou de processo degenerativo dentro do corpo, ou de agentes químicos, físicos ou biológicos que o invadem, ou, ainda, da falha de algum mecanismo regulatório do organismo. Segundo essa visão, doenças podem ser detectadas apenas por métodos científicos.

Partindo do princípio, concernente a esse modelo, de que a saúde e a vida saudável emergirão automaticamente da ciência, os tratamentos médicos consistiriam em esforços para reestruturar o funcionamento normal do corpo, para interromper processos degenerativos, ou para destruir invasores.

A concepção mecanicista do organismo humano levou a uma abordagem técnica da saúde, na qual a doença é reduzida a uma avaria mecânica, e a terapia médica, à manipulação técnica. Em muitos casos, essa abordagem foi bem-sucedida. A ciência e a tecnologia médicas desenvolveram métodos altamente sofisticados para remover ou consertar diversas partes do corpo.

Porém, segundo Porto (1994, p. 20), “a incorporação tecnológica passou a produzir, em graus variáveis, efeitos colaterais, como interferência na relação médico-paciente, novos riscos; iatrogenia; níveis exagerados de especialização; institucionalização dos cuidados de saúde; aumento nos custos dos serviços; distorção na alocação de recursos no sistema de saúde etc.”.

As conclusões de Canguilhem (1990) sobre as relações entre o normal e o patológico tornam mais complexa a abordagem da prática médica. 
Suas reflexões levam ao questionamento da própria prática médica que, impregnada de organicismo e reducionismo, contribuiu para a fragmentação do indivíduo. A conseqüência mais visível dessa fragmentação foi o afastamento médico-paciente. $\mathrm{O}$ autor mostra que a racionalidade anatomoclínica, interessada em enumerar e classificar doenças, revelou-se insuficiente, pois excluiu aspectos importantes do adoecimento do indivíduo.

A vida só tem sentido na pessoa humana individualizada. A abstração da doença leva a uma idealização da prática médica. Tudo se passa como se o médico aprendesse a discorrer sobre as doenças para esquecer o fato definitivo da morte. Esse esquecimento, porém, afasta a medicina de um aspecto essencial da natureza humana: a consciência da fragilidade, a certeza da morte.

A constatação e a compreensão da onipotência e do autoritarismo - talvez tentativas de negar a morte - contribuem para o resgate das subjetividades do paciente e do médico. Para Canguilhem (1990), a razão de ser da medicina é o lidar com a dor, com o sofrimento e com a morte. A superação da visão organicista e reducionista da medicina, através da inclusão do social, do psicológico e da morte, podem contribuir para aproximar a medicina da concepção desse autor. Esses questionamentos estão, de alguma forma, presentes na reformulação dos currículos médicos, apontando, portanto, para uma visão diferenciada e mais abrangente do que aquela voltada somente para as questões orgânicas.

\section{Raízes da medicina social no mundo e no Brasil}

A medicina social, vista como possível alternativa para o modelo excessivamente biológico e tecnológico, não aparece apenas no século XX, em função da especialização e "tecnologização" da medicina e dos problemas decorrentes dessa fragmentação. Na França e na Alemanha, por volta de 1850 , já se concebia a medicina como uma ciência social. Entre os princípios afirmados estava o de que as relações entre saúde e doença e condições econômico-sociais deveriam ser submetidas à investigação científica. Suas bases científicas e ideológicas levaram à apresentação de diversas leis, entre elas, a Lei de Saúde Pública, submetida à Sociedade Berlinense de Cirurgiões em 1849: o Estado deveria providenciar um número de médicos bem treinados para atuar na promoção de saúde e no combate à doença, tratando de implantar o desenvolvimento saudável, tanto físico como mental, do cidadão (Rosen, 1980).

Em 1893, Behring, médico alemão, assinalava que tais idéias mereciam restrições, porque, de acordo com a nascente teoria das doenças infecciosas de Pasteur, o médico poderia trabalhar na sua "especificidade sem a necessidade de um desvio para considerações e reflexões sociais” (Rosen, 1980, p. 78). 
Com o nascimento de novas teorias sobre a gênese da doença Claude Bernard, escola anatomoclínica; René Laennec, ênfase no diagnóstico individual; François Bichat, o estudo das doenças nos tecidos - começavam a existir "filiações" a determinadas escolas, e uma concepção pressupunha a negação às outras (Da Ros, 1995). O que as novas concepções tinham em comum era a negação da medicina como ciência da sociedade. A medicina como ciência social implicava compromisso e redirecionamento econômico do Estado; as novas concepções, por sua vez, além de desonerar o Estado, responsabilizando os indivíduos por sua doenças, necessitavam do desenvolvimento de equipamentos e medicamentos muito mais compatíveis com a lógica capitalista de desenvolvimento.

Enquanto isso se passava na Europa, nas Américas desenvolvia-se um modelo eclético de medicina, com "filiação" a diversas escolas, inclusive com a valorização de conhecimentos populares e místicos (Neto, 1994). Mas, em 1910, Abraham Flexner realizou uma primeira grande avaliação sobre o ensino médico nos Estados Unidos. Embora tenha reformulado e modernizado o ensino médico, nele imprimiu características mecanicistas, biologicistas, individualizantes e de especialização da medicina, com ênfase na medicina curativa e exclusão das práticas alternativas.

Abraham Flexner, professor da Universidade Johns Hopkins, foi convidado pela Fundação Carnegie dos Estados Unidos para desenvolver uma avaliação da educação médica em seu país e no Canadá, no começo do século XX. O objetivo da avaliação era dar ao ensino médico uma base científica sólida.

O resultado dessa avaliação foi a publicação, em 1910, do Relatório Flexner, que, articulado pela American Medical Association, teve como impacto o fechamento de 124 das 155 escolas médicas nos Estados Unidos (Fox, 1980).

Esse relatório serviu de base para o ensino de medicina nos Estados Unidos; nele fixou rigorosas diretrizes, a que se obedece até hoje, e que têm reflexos em várias outras partes do mundo.

As modificações ocorridas nas faculdades de medicina da América Latina a partir de 1950 repetem os conteúdos surgidos desse modelo nos Estados Unidos. O Brasil, até 1950, tinha 16 cursos de medicina. Entre 1950 e 1971, surgiram mais 59 faculdades (Ministério da Educação, 1989) que, por orientação federal, seguiram o modelo "flexneriano".

Com a Reforma Universitária - lei nº 5.540/1968 -, implantada durante o governo militar, oficializou-se a separação entre o chamado currículo básico e o profissionalizante, modificando-se a dinâmica interna dos currículos e favorecendo a lógica do complexo médicoindustrial.

Na década de 1970, movimentos que se indispuseram com a lógica imposta aos cursos e com a prática estimulada na área da saúde unificaram-se e passaram a ser intitulados Movimento Sanitário (Da 
${ }^{1}$ Em 1997, o Governo Federal buscou incentivar processos de organização de pólos de formação, capacitação e educação permanente para pessoal de saúde da família, articulando universidades e demais instituições de ensino com secretarias municipais e estaduais de saúde.
Ros, 1986). O processo que se instalou foi de disputa, nas práticas de saúde e no discurso, pela hegemonia no setor. Em 1988 foi aprovada pela nova Constituição a lei do Sistema Único de Saúde (SUS), que assegurou legalmente os seguintes princípios: integralidade das ações, equilíbrio do conhecimento geral/especializado, determinação social do processo saúde-doença, trabalho interdisciplinar, uso de tecnologia adequada e inclusão de práticas de medicinas ditas alternativas.

Em 1993, o Governo Federal colocou em prática o Programa de Saúde da Família, que garante, além dos pressupostos do SUS, o trabalho comunitário, a territorialização da prática de saúde, a resolubilidade no nível de atenção primária de saúde (APS) e a educação em saúde. ${ }^{1}$

Mas a pergunta que se faz é se esse movimento - que implicou mudança do discurso oficial quanto à prática médica - teve reflexo em termos de modificação da estrutura curricular das faculdades de medicina do Brasil. Na verdade, a divisão do curso de medicina em várias disciplinas estreitamente calcadas numa visão biologicista, a grande ênfase dada às especialidades, o ensino excessivamente teórico e a formação pela qual passa o corpo docente contribuem para que o médico esteja sendo instruído de forma a conceber fragmentariamente a relação saúde-doença.

\section{O processo de reformulação curricular}

No final da década de 1970, professores e alunos da Faculdade de Medicina da UFF, descontentes com o ensino e a aprendizagem ali desenvolvidos, iniciaram um processo de discussão e avaliação do currículo médico. A direção da Faculdade de Medicina, solidária com esse movimento, instituiu um grupo de trabalho, formado por representantes de todos os departamentos envolvidos e de representantes estudantis (Diretório Acadêmico).

Após um ano de trabalho, foi elaborado um documento preliminar de reformulação curricular com vistas a propiciar ampla discussão a respeito. $\mathrm{O}$ processo sofreu várias interrupções e só foi efetivamente retomado em 1983.

No documento preliminar foram fixadas algumas etapas, a serem vencidas a partir das discussões: definição do profissional a ser formado, estudo de documentos relativos a refomulações curriculares, estudo da realidade do Brasil, estudo da capacidade instalada funcional dos serviços públicos de saúde de Niterói e da realidade do ensino.

Após a realização das três primeiras etapas, concluiu-se que havia necessidade de efetuar mudanças nos sistemas de saúde e de educação, já que os profissionais formados por esses sistemas reproduziam deficiências constatadas pelo grupo de trabalho, tais como ausência de compromissos sociais com a população; formação excessivamente teórica, com ênfase nas especialidades médicas e em tecnologias de 
tratamento e de investigação diagnóstica de doenças, em detrimento do conteúdo humanístico e de promoção da saúde.

Concluiu-se, também, que o sistema de saúde não atendia às necessidades básicas de assistência médica da população e que pouca ênfase era dada ao preparo dos professores de medicina, bem como aos métodos de ensino-aprendizagem e ao seu papel educacional. $\mathrm{O}$ ensino era voltado para a doença, predominando aulas teóricas e demonstrativas, utilizando-se situações fictícias em detrimento de práticas reais. As disciplinas foram consideradas excessivamente numerosas e compartimentalizadas; o hospital era valorizado como campo de ensino (Universidade Federal Fluminense, 1990). Parece-nos que essas conclusões já apontavam para uma crítica ao modelo biologicista e "flexneriano" de formação médica.

Em 1977, o professor Hugo Coelho Barbosa Tomassini, do Departamento de Saúde da Comunidade, foi convidado a assumir a Secretaria Municipal de Saúde de Niterói. Com sua equipe, promoveu a reestruturação dessa secretaria, estabelecendo um plano diretor para a implantação e expansão da rede municipal de saúde, estendendo sua cobertura a toda população de Niterói.

Concomitantemente, a UFF promoveu o desenvolvimento do Trabalho Docente Assistencial, através, primeiramente, do Programa Integrado de Saúde Materno-Infantil (PISMI - 76/81) e, a partir de 1982, do Programa de Integração Docente Assistencial em Saúde (PIDAS), com o apoio da Fundação Kellog's e da Organização Pan-Americana de Saúde/Organização Mundial de Saúde (OPAS/OMS).

Como conseqüência dessas iniciativas - que passavam pela mobilização de profissionais de outras instituições de saúde de Niterói (Secretaria Municipal e Estadual, Inamps) e dos setores que discutiam a reforma curricular na universidade -, foi desenvolvida, a partir de 1982, a experiência pioneira das Ações Integradas de Saúde (AIS) no Brasil, intitulada Projeto Niterói (Universidade Federal Fluminense, 1990), precursor do SUS. "No Projeto Niterói, grupos interinstitucionais desenvolveram ações visando a municipalização dos serviços, a gestão colegiada, a universalização da atenção, o sistema de referência e contra-referência, a organização das bases de dados, as análises epidemiológicas e o desenvolvimento de programas" (Silva Jr. et alii, 1996, p. 52).

A Faculdade de Medicina participou ativamente da implantação da comissão executiva local do Projeto Niterói, que buscava articular o Setor Público de Saúde (estado, município, Inamps, UFF), numa atuação integrada, hierarquizada e regionalizada dos Serviços de Saúde.

Professores do Departamento de Saúde da Comunidade, atual Instituto de Saúde da Comunidade, que já atuavam isoladamente em diversas Unidades de Saúde em Niterói e São Gonçalo - através das disciplinas de introdução à saúde comunitária, ciências da conduta, saúde comunitária, internato e residência em medicina social e 
preventiva e da habilitação de enfermagem em saúde pública concentraram-se na zona Norte de Niterói, em 1983. O processo de formação de recursos humanos, na implementação das AIS, originou experiências ricas em conteúdo pedagógico, humanístico e social (idem ibidem).

O Departamento de Saúde da Comunidade promoveu discussões sobre o currículo médico e sobre os currículos de outras áreas de saúde que ofereciam disciplinas voltadas para a atuação conjunta das áreas de capacitação profissional, numa visão de saúde interdisciplinar. Rediscutia-se o papel e a importância da equipe de saúde na formação desses profissionais.

Outros departamentos, como os de Medicina Clínica e MaternoInfantil, ampliaram sua atuação "extramuros", mantendo áreas de estágio para graduação e pós-graduação em unidades primárias da rede pública.

Esse processo, desde seu início, remete-nos à crítica feita ao modelo de formação médica quanto à sua ênfase no aspecto biológico e mecanicista, que resulta em uma formação fracionada e desumanizante. A preocupação com a capacitação profissional interdisciplinar tende a minimizar os problemas da separação do conteúdo médico em especialidades.

O processo de reformulação curricular, então, que havia recomeçado em 1983, evoluiu até a elaboração de sua proposta, em 1992, e posterior implantação, em 1994. Entre os diversos motivos de tais interrupções estão as mudanças de direção dentro da própria universidade e na Secretaria de Saúde de Niterói.

\section{O novo currículo pleno do curso de medicina da UFF}

A reformulação curricular da UFF data de 1992, e sua implantação, de 1994, com a resolução no 37/94 do Conselho de Ensino e Pesquisa (CEP). O processo de reformulação, de mais de dez anos de duração, ocorreu paralelamente às mudanças da rede de saúde de Niterói e do Brasil, no contexto do SUS.

O currículo apresenta-se como um documento teórico do qual constam os objetivos, o detalhamento do modelo curricular e o resumo dos três programas que o compõem - Programa Teórico Demonstrativo (PTD), Programa Prático-Conceitual (PPC) e Programa de Internato e suas respectivas fases. Além dos três programas, desenvolve-se, paralelamente, o Programa de Iniciação Científica, em que se estrutura "uma base de caráter obrigatório e contida no Programa PráticoConceitual, complementada por atividades de natureza inicialmente optativa, as quais no futuro deverão se agregar definitivamente ao corpo curricular" (Universidade Federal Fluminense, 1992).

A seguir, o documento traz a descrição dos objetivos que se colocam para o curso de medicina da UFF, que são:

- a busca da interdisciplinaridade; 
- a necessidade de repensar constantemente os conhecimentos da área médica, decorrência da velocidade do desenvolvimento da ciência e da tecnologia;

- a formação de médicos que sejam humanistas, técnicos competentes, com conhecimentos, atitudes e comportamentos éticos, habilidades psicomotoras e compromisso social.

A parte relativa à avaliação se refere tanto à análise do próprio currículo quanto à avaliação proposta pelo currículo para os alunos, que é descrita da seguinte forma:

A avaliação da estrutura curricular dar-se-á ao final de cada etapa vencida e terá seu momento culminante no final de sua total implantação. Haverá uma constante sondagem de opinião, a ser respondida por alunos, professores, coordenador do curso de medicina e profissionais da rede de serviços públicos que orientarão o trabalho supervisionado. A análise dos resultados poderá levar a conclusões quanto à necessidade de reformulação ou manutenção do currículo adotado.

Quanto à avaliação da nova metodologia, propõe:

A avaliação da metodologia do ensino teórico-prático e o desempenho dos alunos envolverá dois aspectos: a auto-avaliação e a heteroavaliação. Tanto professores quanto alunos participarão da avaliação do processo ensino-aprendizagem, das disciplinas, das fases do trabalho supervisionado, das etapas do estágio curricular e do currículo pleno. As conclusões poderão levar à reformulação e/ou inovação da metodologia de ensino e à promoção do aluno de uma etapa para outra e, finalmente, ao término do curso.

Após esta breve descrição da apresentação do Documento do Currículo Pleno da UFF, passamos a uma análise de seu conteúdo, que será feita a partir de questões fundamentais de currículo: marco conceitual, modelo curricular, integração teórico-prática, interdisciplinaridade, modelo de avaliação, preparação de recursos humanos. Através da análise desses pontos do currículo, bem como de sua abordagem, pretendemos averiguar sua coerência interna, entendendo coerência interna como a concordância entre a lógica dos pressupostos teóricos e a proposta de execução em todas as etapas.

Em relação às considerações preliminares e justificativa, nosso primeiro questionamento diz respeito às referências bibliográficas. No texto, não são citadas as fontes de consulta bibliográfica nem são feitas referências. O único momento em que há referência teórica é na apresentação do modelo analítico curricular, embora não se apresente, de fato, a referência bibliográfica. Além do aspecto formal, essa falta de referências pode indicar uma deficiência quanto a não serem assumidas as linhas teóricas e conceituais. Trata-se de um aspecto importante, uma vez que partimos 
do princípio de que um currículo nunca é neutro e sempre reflete as forças político-ideológicas que o apóiam ou que se lhe opõem.

Apontamos, ainda, como problema do texto das considerações preliminares e justificativa, a falta de contextualização. $\mathrm{O}$ período pelo qual passou a reformulação curricular coincide com a mudança da demanda do papel social do profissional de saúde, pois corresponde à implantação do SUS. Compõe, também, o cenário político desses anos uma crise no modelo de formação médica; não há, entretanto, contextualização dessa discussão. Consideramos necessária, em documentos de propostas curriculares, a definição das tendências que organizam o campo de conhecimento, como dado fundamental para a delimitação do marco conceitual.

No documento é feita uma crítica ao modelo curricular e ao marco conceitual seguido pelos cursos de medicina, crítica essa que apresenta características comuns às já mencionadas neste artigo. As características do currículo médico criticadas nas considerações preliminares do documento são:

- forte ênfase dada à doença, e não à saúde;

- desvinculação entre ensino básico e profissional, além do distanciamento físico entre as duas áreas;

- freqüente despreparo do profissional médico em relação ao aspecto pedagógico e didático, o que implica a utilização de uma metodologia pouco adequada ao desempenho da função docente;

- ênfase no conteúdo a ser ensinado, sem a preocupação com a aprendizagem real do aluno;

- massificação do ensino resultante do grande afluxo de candidatos que ingressam nas escolas superiores, sem obedecer a uma planificação adequada;

- carência de desenvolvimento de uma metodologia científica que integre conhecimento clínico com conhecimento epidemiológico;

- predomínio do uso de situações fictícias em salas de aula e laboratórios, em detrimento de situações reais, tanto no ciclo básico quanto no ciclo profissional;

- excessivo número de disciplinas, dadas de forma fragmentada, sem integração interdisciplinar;

- utilização das enfermarias como única possibilidade de contato aluno-paciente, o que gera uma relação profissional exagerada, que dificulta a aprendizagem do aluno e a recuperação do paciente;

- valorização excessiva da especialização, resultando em prejuízo para a formação integral do médico.

O documento apresenta, portanto, uma proposta de alteração dessas características. Procuraremos, então, verificar sua coerência interna, tentando identificar as modificações propostas no modelo curricular (disciplinas e ementas). 
Ainda no começo do documento - nas considerações preliminares e justificativa -, é apontado um "freqüente despreparo do profissional médico em relação ao aspecto pedagógico e didático, implicando a utilização de uma metodologia pouco adequada ao desempenho da função docente". Surge o questionamento de como esse novo currículo poderia mudar tal realidade, uma vez que o documento não aponta para a efetivação de uma estratégia de preparação do corpo docente.

A respeito do preparo do corpo docente, Giroux (1983, p. 258) afirma:

Para os professores implementarem uma noção mais abrangente de educação para a cidadania, eles terão que entender não apenas as ligações que existem entre o currículo oculto e o formal, mas também as conexões complexas que existem entre o currículo e os princípios que estruturam modos semelhantes de conhecimento, e as relações sociais na sociedade maior.

Consideramos esse aspecto fundamental, pois trata-se de crítica comum a vários cursos de medicina e reivindicação freqüente dos estudantes da área médica. É o que se pode constatar no depoimento da representante estudantil, do diretório acadêmico da UFF, em 1992: "Alguns professores vêm dar as aulas sem nenhuma preocupação com a questão didática. Chegam e, mesmo antes de dizer 'bom dia', começam a escrever no quadro-negro, e nós, os alunos, temos que passar a aula copiando ... . Muitas vezes nem sobra tempo para algum questionamento mais subjetivo."

Buscaremos, a seguir, identificar a coerência interna do currículo no sentido de viabilizar a preparação diferenciada do profissional médico, através da análise da estrutura curricular e das disciplinas propostas.

Inicialmente, o documento Detalhamento do Modelo Curricular (Universidade Federal Fluminense, 1992, p. 8) demonstra que a parte fundamentalmente prática aumenta à medida que a parte fundamentalmente teórica diminui. Ainda na descrição desse modelo, destacamos:

a inter-relação entre os conteúdos teóricos e práticos distribuídos nas etapas teórico-demonstrativas e prático-conceituais: na primeira associa-se o conteúdo teórico a uma demonstração prática executada pelos docentes e, na segunda, completa-se uma prática executada pelos alunos, sempre baseada em uma discussão conceitual das ações e de seu referencial teórico.

As características mais importantes a serem destacadas nesse modelo seriam a integração do ciclo básico ao profissional através das atividades práticas desde o começo do curso; a ampliação do campo de estágio para além do Hospital Universitário Antônio Pedro, propiciando maior 
contato dos alunos com a comunidade desde o começo do curso; o envolvimento de equipes interdisciplinares na organização e desenvolvimento das atividades - e um exemplo citado é a constituição de equipes de coordenação das atividades prático-conceituais envolvendo os vários departamentos, embora, segundo depoimentos de professores do Instituto de Saúde da Comunidade, a equipe de coordenação não tenha envolvido vários departamentos, mas apenas esse instituto; a valorização dos aspectos éticos da profissão, da liberdade de discussão ideológica, metodológica e, conseqüentemente, o questionamento das 'verdades científicas'.

Para começar a análise crítica pelo último item aqui destacado, perguntamos: sabendo-se que os professores dos cursos de medicina são, em sua maioria, médicos, e que, para desempenharem a tarefa de ensinar não lhes é exigida qualquer formação pedagógica; sabendo-se ainda que a formação vem sendo feita dentro do modelo médico que valoriza as "verdades científicas", como se garantirá a "liberdade de discussão ideológica, metodológica e o questionamento das 'verdades científicas" que não estavam sendo garantidos antes?

De acordo com o pensamento de Fleck (1986, pp. 75, 77), as verdades científicas têm datas e momentos específicos:

$\mathrm{Na}$ história do conhecimento científico não existe nenhuma relação lógico-formal entre as relações e suas provas: as provas se acomodam às concepções tão freqüentemente quanto as concepções às provas... . cada época tem concepções dominantes, resíduos das do passado e germens das do futuro.

O autor utiliza vários exemplos onde as "verdades" consideradas "científicas”, em cada momento histórico, são substituídas por outras "verdades". Um dos exemplos é o caso da teoria clássica das doenças infecciosas. Segundo tal teoria, toda doença infecciosa era causada por um agente vivo e diminuto, e não se podia ver, ainda, que esse agente existisse também nas pessoas saudáveis; só muito mais tarde se descobriu a noção dos portadores sãos. Depois veio o "segundo golpe": a variabilidade dos microrganismos. Nos tempos de Koch, não se podia aceitar nenhuma variabilidade. Foi necessário que se passasse um certo tempo para que as múltiplas observações desse fenômeno fossem aceitas. Fleck continua: "O terceiro golpe na teoria clássica da infecção foi proporcionado pela teoria dos vírus filtráveis, pois só então se demonstrou que a infecção clássica, ou seja, a invasão dos agentes causais, é um caso excepcional no mecanismo de produção da infecção."

A partir do exemplo utilizado por Fleck, indagamos se, para garantir o questionamento das "verdades científicas" durante o curso médico, não haveria a necessidade de se realizar uma preparação em que os novos parâmetros propostos pelo currículo atual pudessem ser vivenciados, aprendidos, aplicados? Cabe ressaltar que, no documento 
em pauta, não está descrito como se pretende capacitar os professores do curso de medicina para trabalhar com a nova proposta curricular, nem se esse currículo foi implantado com apoio e/ou unanimidade de todos os departamentos.

Em entrevista feita com professores e responsáveis pela implantação do currículo, percebe-se que não houve consenso de todos os departamentos da Faculdade de Medicina quanto à implantação do mesmo. Através de depoimentos do coordenador de curso e de professores de alguns departamentos, feitos em jornal interno da UFF (1995, p. 7), em matéria intitulada 'Currículo novo expõe confronto entre duas visões de mundo', fica clara a insatisfação de professores do Departamento de Cirurgia Geral e Especializada e do Departamento Materno-Infantil. Foi mencionado, também, que o Departamento de Medicina Clínica votou contra a implantação do novo currículo: o "chefe do departamento de Medicina Clínica recorda que seu departamento votou contra o novo currículo e critica o que considera urgência na implantação. Lembra que o departamento sugeriu uma fase de transição de dois anos para melhor adaptação, num sistema de mudança gradual."

O coordenador do curso de medicina, por sua vez, considera legítimas as preocupações dos professores, mas atribui grande parte das críticas à desinformação e à falta de diálogo entre os departamentos. Denuncia, ainda, "uma grande apatia e ausência de parte dos professores nas reuniões em que se organizam os horários e programas dos períodos. ... O currículo não se mostrou ruim porque nem chegou a ser inteiramente posto em prática" (idem, ibidem, p. 8). Não há dúvidas, portanto, de que não houve consenso quanto ao novo currículo.

A dificuldade de diálogo entre os departamentos da Faculdade de Medicina poderia ter entre outras explicações, segundo Fleck (1986), o fato de esses departamentos representarem as especialidades médicas, que constituem diferentes 'coletivos de pensamentos', com distintos 'estilos de pensamento'. As concepções de medicina e os objetivos da formação médica parecem ter diferenças para cada uma das áreas, o que prejudica o diálogo. Para que haja intercâmbio de idéias, é necessário também o esforço de criação de um diálogo abrangente e, de fato, interdisciplinar. São justamente as diferenças que podem tornar necessário e frutífero o intercâmbio.

Ainda na busca de uma análise das características que, neste trabalho, foram consideradas as mais importantes do currículo, a seguir comentaremos o fato de as atividades práticas serem oferecidas desde o começo do curso, bem como o de o campo de estágio ter sido ampliado para além do Hospital Universitário. Essa modificação, além de significar maior integração teoria-prática, propicia maior contato dos alunos com a comunidade, possibilitando sua inserção no processo de trabalho das Unidades de Saúde, cuja rotina de serviço, complexa e dinâmica, é bem diferente daquela dos hospitais universitários. 
Segundo relato de professor do Instituto de Saúde da Comunidade, em 1995, a inserção na comunidade, mesmo antes de o aluno exercer qualquer atividade identificada como médica - sua inserção se faz a partir das disciplinas introdutórias - lhe permite o contato com o ser humano em sua realidade e vida.

Para apreender o envolvimento dos departamentos com a nova proposta, é necessário verificar até que ponto as disciplinas e suas ementas se modificaram - ou se apenas mudaram seus nomes.

Neste ponto, aproveitamos para assinalar o fato de as ementas estarem descritas em forma de tópicos. Considerando a ementa como "uma descrição resumida dos conteúdos e da forma como serão trabalhados e não uma seqüência de itens de programas" (Paixão, 1995), parece-nos estar mal utilizado esse elemento da proposta.

O PTD está dividido em quatro fases, cada uma com dois períodos letivos. Sua carga horária é de 3.195 horas e 213 créditos teóricos. As matérias do ciclo básico se desdobram em disciplinas, como grandes áreas que, por sua vez, se desdobram em subáreas. Por exemplo, a matéria ciências biofisiomorfológicas se subdivide em nove disciplinas: biologia geral I, biologia celular e molecular, neurobiologia, fisiologia VI, fisiologia VII, morfologia I, morfologia II, morfologia III e anatomia médico-cirúrgica.

No ciclo profissional, a matéria medicina integral I, por exemplo, se desdobra nas disciplinas medicina integral do adulto e do idoso I, II , III e IV. Em nota de rodapé, há uma observação que esclarece que a matéria medicina integral I engloba o conteúdo das matérias obrigatórias do currículo mínimo: estudo da saúde coletiva; iniciação ao exame clínico; bases da técnica cirúrgica e anestesiologia; obstetrícia e ginecologia; pediatria; ciências fisiológicas; psiquiatria; patologia e clínica dos órgãos e sistemas; medicina legal; terapêutica; deontologia e gerontologia.

A seqüência aconselhada da distribuição das disciplinas do PTD pelos períodos mostra que o aspecto biológico é mantido no começo do curso. A primeira disciplina descrita é neurobiologia, a segunda e terceira são biologia celular e molecular e biologia geral.

Essa abordagem pode ser um indício de que o modelo utilizado é o biomédico, o que, a nosso ver, se explica pelo fato de ser um currículo da Faculdade de Medicina. Talvez se trate de um currículo biomédico mais humanista e, de certa forma, preocupado com a manutenção do ser humano em sua totalidade, e não dividido em partes.

Podemos exemplificar com o fato de as disciplinas estarem divididas por critério de faixas etárias e não por partes do corpo de cada faixa etária. Por exemplo, a disciplina em que se estudam as características e problemas dos olhos, oftalmologia, não está mais isolada. No currículo antigo estudavam-se as questões referentes aos olhos em todas as idades. Já no novo currículo a oftalmologia é estudada no contexto do aprendizado do corpo por inteiro, por fases da vida ou faixas etárias (criança, adolescente, adulto e idoso) nas disciplinas medicina integral 
da criança e do adolescente e medicina integral do adulto e do idoso. O núcleo de organização da disciplina passa a ser o ser humano, em suas fases da vida, e não mais a parte do corpo, no caso, os olhos.

Quanto à carga horária das disciplinas, o quadro comparativo entre os dois currículos permite observar que os créditos aumentaram de 275 para 382, o que significa aumento da carga horária. Além disso, há um aumento da carga horária na parte teórica e não apenas na prática. $\mathrm{O}$ aumento da carga horária prática se justifica pelo novo enfoque do currículo, com ênfase na prática, mas a que se deve o aumento da carga teórica?

Uma justificativa pode ser a evolução do conteúdo médico e da própria medicina. Devemos, porém, ponderar sobre o que esse aumento de carga horária significa na vida acadêmica do estudante de medicina, pois a carga horária total do curso passa de 7.320 horas-aula para 9.135 horas-aula. Ou seja, há um aumento de 1.816 horas-aula, isto é, de cerca de $25 \%$.

Ora, para averiguar se há sobrecarga de aulas para os alunos, é necessário examinar a carga horária semanal. $\mathrm{O}$ fato de o currículo ter aumentado sua carga horária pode demonstrar um aumento de sua extensão e não de sua intensidade, já que esse curso é dado em vinte semanas por período.

Em todos os períodos, houve aumento de carga horária teórica semanal. Esse aumento variou de $200 \%$, no primeiro período, a $20 \%$, no sexto. A carga horária prática semanal não aumentou em todos os períodos: oscilou entre aumentos de até $157 \%$ e quedas de mais de $160 \%$.

Porém, em função das especificidades do novo currículo, a simples comparação de carga horária não abarca suas diferenças. Ora, no currículo anterior, as disciplinas demonstrativas eram consideradas práticas e, em sua maioria - segundo depoimento do coordenador do curso (em 1996) -, consistiam de exemplificações por parte dos professores e não de experimentação por parte dos alunos. Poderíamos, então, considerar as aulas ditas práticas do currículo antigo como teóricas, se analisadas à luz do novo modelo curricular. A partir desse novo parâmetro, a comparação das cargas horárias semanais das disciplinas dos dois currículos indica queda da carga teórica e aumento da carga prática.

Uma das principais críticas e preocupações que cercam a análise de reformulações curriculares diz respeito ao acréscimo excessivo de carga horária, a chamada sobrecarga ou "inchaço" do currículo. No caso do currículo médico, o primeiro problema quanto ao aumento de carga horária é relativo ao tempo que os alunos terão para estudar, processar o aprendizado e viver sua vida extra-acadêmica. Quando se propõe um currículo interdisciplinar, os alunos do curso devem ter tempo, também, para realizar, na prática, a interdisciplinaridade. Além disso, tem sido uma reclamação constante do corpo discente a falta de tempo para manter uma boa saúde física e mental. Assim, o aumento excessivo 
de carga horária talvez seja um ponto desfavorável dessa reformulação. Transcrevemos um trecho de entrevista com um aluno do sétimo período, em 1992, em que ele reclama dessa carência:

Com a carga horária intensa que somos obrigados a cumprir, às vezes não dá nem para almoçar... e como eu posso dizer para um paciente que ele deve se alimentar melhor ou que seu filho deve ter horário para o almoço, se eu mesmo não o tenho? Afinal, se quero falar sobre saúde, trabalhar com a saúde da população, tenho que ser coerente!.

Estudos realizados em sala de aula recomendam uma proporção de horas de estudo individuais por cada hora teórica de aula de três para um. Ou seja, o estudante necessita, para poder assimilar o conhecimento adquirido em uma hora de aula teórica, de três horas de estudo. A proporção para as horas de aulas práticas se inverte, pois se considera que o conteúdo já estará sendo assimilado durante a experimentação prática e, portanto, o aluno necessitará de menos horas para assimilar o conteúdo (Paixão, 1996). A partir dessas proporções se pode questionar o tempo de assimilação que terá o aluno do curso de medicina da UFF, já que, em algumas disciplinas, chegará a ter mais de trinta horas semanais de aula.

Onde entra a interdisciplinaridade? Não está descrito, no currículo, como se dá a prática interdisciplinar. Há profissionais de diversas áreas trabalhando em conjunto? Isso está proposto nos objetivos, mas não fica claro se realmente houve um trabalho interdisciplinar para a elaboração e implantação desse currículo, nem se todos os departamentos se envolveram na reformulação e implantação do mesmo. Os depoimentos já citados não mostram que isso tenha acontecido.

Através de depoimentos do coordenador do Grupo de Estudos para a Reformulação Curricular e de professores do Departamento de Saúde da Comunidade - atual Instituto de Saúde da Comunidade , no ano de implantação do currículo (1994), alguns departamentos não participaram das discussões para a reformulação, outros nem conseguiram reunir-se internamente para analisar a proposta e emitir seu parecer; outros, ainda, se opuseram a essa proposta. A interdisciplinaridade, portanto, sofreu obstáculos e dificuldades desde a fase de elaboração do currículo. Identificamos esse tipo de problema enfrentado pela Faculdade de Medicina como reflexo do que Fleck (1986) denomina 'incomensurabilidade de idéias'. Os diversos departamentos da referida faculdade correspondem às diversas especialidades do campo médico. Cada campo tem uma determinada área de atuação e, conseqüen-temente, um estilo de pensamento. Essa diversidade de estilos de pensamentos cria uma diversidade de coletivos de pensamento e, finalmente, uma incomensurabilidade de idéias. 
Atualmente, o currículo - que já formou sua primeira turma em dezembro de 1999 - está aos poucos conseguindo avançar no sentido da integração de departamentos. Isso vem se dando, segundo depoimento de professor do Instituto de Saúde Comunitária (março de 2000), como reflexo da melhor estruturação das disciplinas e do melhor domínio, por parte dos professores, do que seja a proposta curricular e de suas etapas.

Persistem as dificuldades - que existem desde a implantação do currículo - com a organização do trabalho de campo. Durante o primeiro ano do curso ainda não é possível realizar, plenamente, as atividades de campo previstas. $\mathrm{Na}$ opinião do professor entrevistado, o problema continua centrado numa questão de preparação e treinamento de professores e tutores, tanto para que a proposta seja claramente compreendida quanto para que os profissionais sejam capazes de trabalhar melhor em suas atividades.

Numa pesquisa de avaliação da nova proposta curricular - que está começando a ser desenvolvida por uma equipe de professores do Instituto de Saúde Comunitária -, os 44 alunos formados na primeira turma responderam a um questionário, manifestando-se favoravelmente ao currículo. Apesar de muitas críticas aos primeiros semestres do curso, os alunos consideram que sua postura profissional e a compreensão da realidade social foram fortemente influenciadas por esse currículo. A Faculdade de Medicina passou por uma avaliação do MEC no ano passado, e a proposta didático-pedagógica do novo currículo obteve a nota máxima, representada pelo conceito $\mathrm{A}$.

\section{Conclusão}

Ao analisarmos o documento de reformulação curricular da UFF, consideramos que houve avanços importantes no sentido de questionar o modelo biomédico de formação. Acreditamos, porém, que a profissão médica requer conhecimentos da área biológica, e não se pode eliminar o aspecto biomédico na formação desse profissional.

Avaliamos, contudo, ser necessária a introdução de conteúdos da área de ciências sociais, como instrumento para a formação do médico capaz de atuar nos problemas de saúde mais recorrentes da população brasileira, bem como no domínio das tecnologias. O médico, para lidar com a dicotomia entre a tecnificação da prática médica e o aumento das especializações, por um lado, e o aumento crescente do agravo de problemas básicos de saúde da população, por outro, deve estar apto a questionar seu papel diante das duas (ou mais) vertentes e a atuar no sentido de melhorar a qualidade de vida e de reduzir os níveis do adoecer. Nesse sentido, parece-nos que o curso de medicina da UFF indica uma reformulação capaz de avançar nos aspectos citados, principalmente através de seu modelo curricular.

A introdução precoce do estudante nas aulas práticas, mesmo que inicialmente ainda não seja visto como médico, contribui para a 
transformação da postura desse futuro profissional, tornando-a mais ética. Os alunos estão, desde o primeiro período, divididos em pequenos grupos (oito alunos), e, a partir do aprendizado dos determinantes históricos, sociais e ideológicos do processo de saúde-doença e do meio ambiente (UFF, 1992), entram em contato com os conteúdos referentes a um grupo populacional real de Niterói. Dessa forma, elaboram o conhecimento de forma teórico-prática e vivenciada.

Assim, ao conhecer uma comunidade e sua população desde o começo do curso, o aluno talvez venha a ter mais condições de assimilar os conteúdos teóricos, na perspectiva da compreensão do ser humano em sua totalidade e não mais dividido em partes, como acontecia com o tipo de formação anterior. Conseqüentemente, deverá adotar uma postura mais ética na relação médico-paciente e estar melhor qualificado para enfrentar as dificuldades cotidianas de sua profissão.

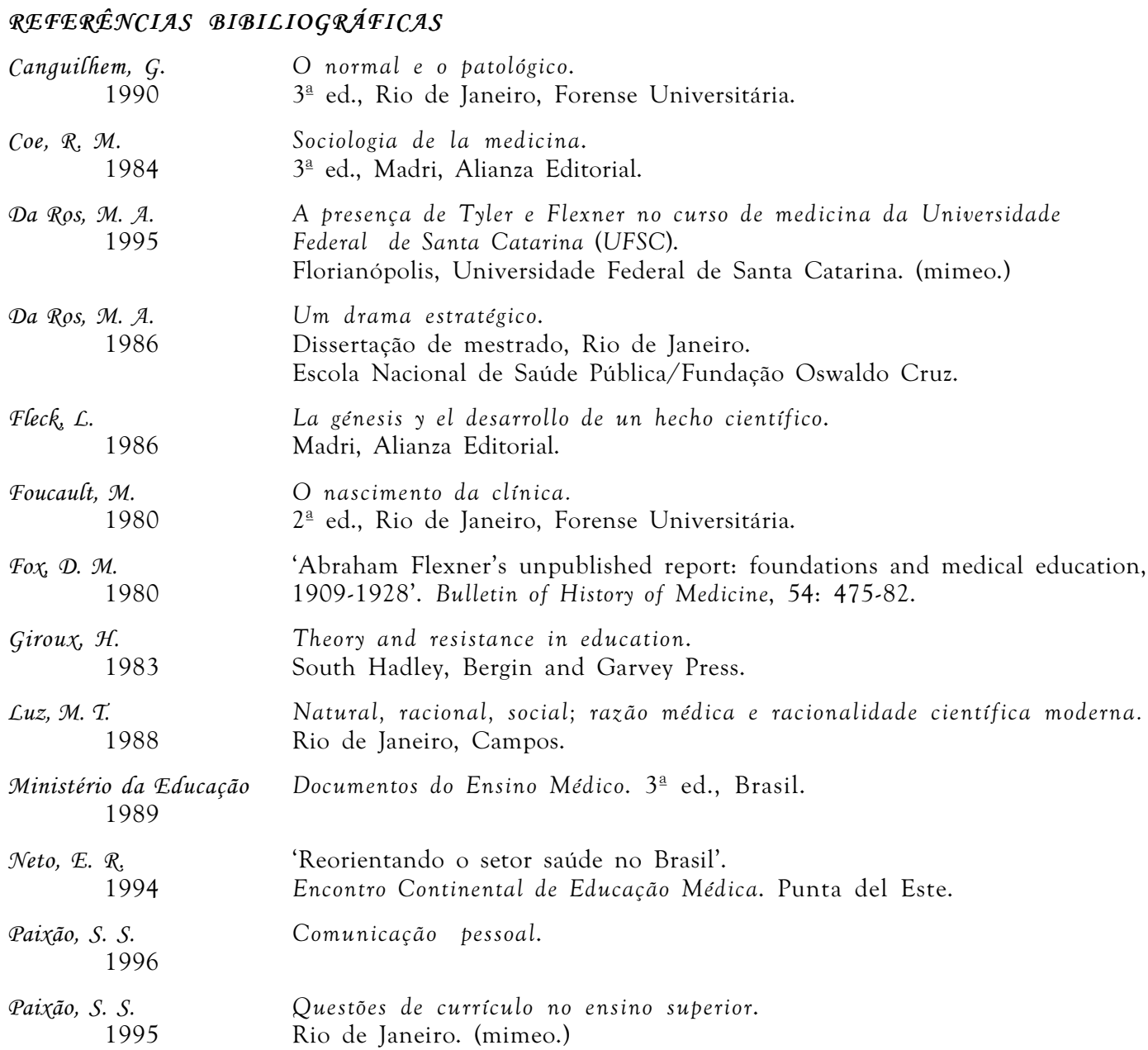

Canguilhem, $G$. 1990

Coe, R. M.

1984

Da $\operatorname{Ros}, \mathcal{M} . \mathcal{A}$.

1995

Da Ros, M. A.

1986

Fleck, $\mathcal{L}$.

1986

Foucault, $\mathcal{M}$. 1980

Fox, D. $\mathcal{M}$.

1980

Giroux, $\mathcal{H}$.

Luz, M. T.

1988

Ministério da Educação 1989

Neto, E. R 1994

Paixão, S. S. 1996

Paixão, S. S. 1995

O normal e o patológico.

$3^{\text {a }}$ ed., Rio de Janeiro, Forense Universitária.

Sociologia de la medicina.

3a ed., Madri, Alianza Editorial.

A presença de Tyler e Flexner no curso de medicina da Universidade Federal de Santa Catarina (UFSC).

Florianópolis, Universidade Federal de Santa Catarina. (mimeo.)

Um drama estratégico.

Dissertação de mestrado, Rio de Janeiro.

Escola Nacional de Saúde Pública/Fundação Oswaldo Cruz.

La génesis y el desarrollo de un hecho cientifico.

Madri, Alianza Editorial.

O nascimento da clinica.

$2^{\underline{a}}$ ed., Rio de Janeiro, Forense Universitária.

'Abraham Flexner's unpublished report: foundations and medical education, 1909-1928'. Bulletin of History of Medicine, 54: 475-82.

Theory and resistance in education.

South Hadley, Bergin and Garvey Press.

Natural, racional, social; razão médica e racionalidade cientifica moderna. Rio de Janeiro, Campos.

Documentos do Ensino Médico. 3a ed., Brasil.

'Reorientando o setor saúde no Brasil'. Encontro Continental de Educação Médica. Punta del Este.

Comunicação pessoal.

Questões de curriculo no ensino superior. Rio de Janeiro. (mimeo.) 
Porto, M. A. T. 1994

Rosen, $G$.

1980

Silva Jr., A. G.; Pires, A. C.; Marins, J. J. J. e Tomassini, $\mathcal{H}$. C. B

1996

Universidade Federal Fluminense

1995

Universidade Federal Fluminense

1992

Universidade Federal Fluminense

1990

Vaitsman, $\mathcal{J}$. 1992

Vieira, M. M.

1991
'A circulação do sangue, ou o movimento no conceito de movimento'. História, Ciências, Saúde - Manguinhos, vol. I (1), pp. 19-34.

Da polícia médica à medicina social.

Rio de Janeiro, Graal.

'As experiências de articulação universidade-serviço-sociedade em Niterói, RJ'. Divulgação, 12: 51-56.

Casarão - Jornal Laboratório do Curso de Jornalismo.

Niterói, UFF/IACS, Departamento de Comunicação Social, vol. 17.

Proposta de Currículo Pleno. Niteroí,

Faculdade de Medicina/Centro de Ciências da Saúde/UFF.

Programa de capacitação extramural em saúde da UFF.

Projeto zona Norte de Niterói. Niterói, CCM/Colegiado Gestor do IAV-CEM. (mimeo.)

'Saúde, cultura e necessidades'. Em S. F. Teixeira (org.), Saúde coletiva? Questionando a onipotência do social. Rio de Janeiro, Relume-Dumará.

Reflexões sobre racionalidades médicas: dilemas de um clinico.

Dissertação de mestrado, Rio de Janeiro, Instutito de Medicina Social, Universidade do Estado do Rio de Janeiro.

Recebido para publicação em agosto de 1998. Aprovado para publicação em junho de 2000. 